\title{
La protección de la dignidad de la mujer viuda en la sociedad española
}

\author{
The protection of widowed women's dignity in Spanish society
}

\author{
Milagros María Otero Parga ${ }^{1}$ \\ ${ }^{1}$ Universidad de Santiago de Compostela, España. \\ ORCID: 0000-0002-2259-2030 \\ Correo: milagros.otero@usc.es \\ Recibido: 11/12/2019 \\ Aceptado: 18/05/2020
}

\section{Resumen:}

La mujer a lo largo de la historia ha sido relegada a desempeñar un papel inferior al del hombre: no podía disponer de su persona ni de sus bienes; tampoco podía desarrollar su vida en clave de igualdad, como titular de idénticos derechos y deberes. Esa situación es más complicada para las mujeres viudas que, además de sufrir las discriminaciones propias de su sexo, tienen que asumir una pérdida que supone en muchos casos tener que ocuparse exclusivamente de su familia. Esta situación está cambiando, pero es preciso tomar medidas que solventen el problema. Este artículo realiza un recorrido por la consideración de la mujer en el Derecho histórico español con el propósito de compartir algunas medidas de protección a las mujeres viudas en las que está trabajando actualmente el gobierno de la comunidad autónoma española de Galicia. Son medidas que pueden servir como punto de partida para mejorar la situación de las mujeres viudas, no solo en toda España, sino también en el resto del mundo.

Palabras clave: dignidad; mujer; viuda; derechos humanos; feminismo.

\begin{abstract}
:
Throughout history, women have been relegated to a role that is inferior to that of men: they could not dispose of their person or their property; nor could they live their lives on an equal footing, as holders of identical rights and duties. This situation is more complicated for widowed women who, in addition to suffering the discrimination that is specific to their sex, have to assume a loss that in many cases means having to take sole charge of their family. This situation is changing, but measures must be taken to address the problem. This article reviews the consideration of women in Spanish historical law with the aim of sharing some measures of protection for widows that the government of the Spanish autonomous community of Galicia is currently working on. These are measures that can serve as a starting point for improving the situation of widowed women, not only throughout Spain, but also in the rest of the world.
\end{abstract}

Keywords: dignity; women; widow; human rights; feminism. 


\section{Introducción}

Vivimos en una sociedad que trata de recuperar el camino de la igualdad por razón de sexo, lamentablemente perdido en otros momentos de la historia. Poco a poco, los seres humanos van tomando conciencia de que las personas no somos idénticas, sino diferentes $^{1}$. Esta diferencia no debe ser un problema si se basa en razones objetivas regidas por los principios de mérito y capacidad y no por la consideración sexual. Un ser humano no es mejor ni peor por el hecho de ser mujer $\mathrm{u}$ hombre ${ }^{2}$, y por lo mismo, debe ser tratado en todo caso con igualdad ante la ley, respetando después las desigualdades que vengan determinadas por sus capacidades. La diferencia de trato nunca debe sustentarse en la condición sexual, ya que esta no influye ni en la inteligencia, ni en la voluntad, ni en la capacidad de esfuerzo o en la forma de vivir su responsabilidad ${ }^{3}$ que acredite cada persona.

El camino de la equiparación del sexo femenino y masculino ha empezado a recorrerse, pero aún queda mucho por andar. Es preciso educar en la igualdad y en la diferencia. Es preciso hacerlo partiendo de cero y prestando especial atención a la educación de las nuevas generaciones ${ }^{4}$, que deben asumir como algo normal y habitual, que los seres humanos somos personas iguales (al menos en dignidad ontológica ${ }^{5}$ ), con independencia de tener el sexo que cada uno reconozca como propio ${ }^{6}$.

En el camino de la igualdad existen todavía muchos obstáculos que remover y las mujeres suelen salir peor paradas en general. Pero incluso dentro de las mujeres hay

\footnotetext{
${ }^{1}$ Siempre que entendamos la diferencia dentro de los límites legales, respetando el hecho de que todos los seres humanos somos titulares de "derechos (que) se traducen en imperativos éticos emanados de la naturaleza del hombre que se traducen en el respeto a su vida, dignidad y libertad en su dimensión de persona o ente auto teleológico" (Burgoa, 2002, p. 51).

${ }^{2} \mathrm{Al}$ contrario, hombres y mujeres deben tener los mismos derechos humanos pues estos acompañan a todo ser humano "por su naturaleza y dignidad". Estos derechos "le son inherentes y lejos de nacer de una concesión de la sociedad política, han de ser por ésta consagrados y garantizados" (Truyol Serra, 1984, p. $11)$.

${ }^{3}$ Los seres humanos somos en cambio diferentes en cuanto a dignidad ética. Tal como afirma Nino: "las personas deben ser juzgadas y tratadas, para ciertos fines sobre la base exclusiva de sus acciones voluntarias" (1991, p. 422).

${ }^{4}$ Porque como dice Imbert: "el respeto por los derechos humanos no es competencia tan solo del Derecho. Las violaciones de los derechos humanos no sólo son violaciones de la ley. Y la ley no es el único medio de asegurar el respeto de los derechos humanos" (1986, p. 84).

${ }^{5}$ Sobre este tema, ver Puy Muñoz $(1978,1983)$.

${ }^{6}$ Es un problema de libertad y concretamente de los límites que es legítimo imponer a este derecho porque, como afirma Dworkin: "para proteger la igualdad se necesitan leyes, y las leyes son, inevitablemente, compromisos que afectan a la libertad" (1984, p. 382).
} 
algunas cuyas condiciones vitales suelen ser todavía más difíciles: las viudas. A las mujeres que han perdido a la pareja que habían elegido, aquella en la que se apoyaban, y con la que pensaban desarrollar su vida, acompañándose tanto en el ámbito afectivo como en el económico y social. Esas personas suelen estar aún más desamparadas que el resto, porque a su condición de mujer se une la pérdida que experimentan y en muchos casos la necesidad de encontrar una manera de vivir y de ocuparse de su familia, que antes tenían cubierta.

\section{La consideración de la mujer en el Derecho histórico español}

La vida de las viudas y de las mujeres en general, ha cambiado mucho en los últimos tiempos. Los seres humanos somos iguales en derechos y obligaciones y afortunadamente diferentes en todo lo demás, pero uno a uno. Cada ser humano debe valorarse por lo que es, con independencia de su condición de hombre o mujer. La voluntad, la inteligencia, el trabajo, el espíritu de sacrificio y sus antónimos, es decir, la indolencia, la vagancia, o incluso la maldad, no tienen sexo, y por eso cada individuo debe ser considerado de forma singular e independiente.

Sin embargo, tradicionalmente el papel que la sociedad reservó a las mujeres fue diferente del que otorgó a los hombres. La mujer era considerada más delicada, más frágil, menos capacitada para estar fuera de la casa y por lo mismo se le asignaban únicamente las labores domésticas. El ser humano mujer no podía elegir, no podía vivir con libertad, de modo que no podía desarrollarse plenamente como persona. Esa situación limitaba el ejercicio de su dignidad y el de la justicia ${ }^{7}$.

Hasta hace poco tiempo la mujer no tenía derecho a elegir la forma de desarrollar su propia vida. Le estaban vedados muchos trabajos ${ }^{8}$. No podía disponer de su patrimonio. Si estaba casada, porque debía hacerlo con permiso del marido. Si estaba soltera, porque quien podía disponer de sus bienes e incluso de su propia persona era su padre o incluso un hermano. La mujer era considerada únicamente en su faceta de madre de familia, de esposa y de ama de casa, y no podía actuar libremente ni siquiera para decidir si

\footnotetext{
${ }^{7}$ De ese modo quedaba limitado el derecho "a recibir el trato que le corresponde (a cada individuo) como persona y al mismo tiempo el que merece, de forma individualizada, de acuerdo con el tipo de persona que haya decidido ser" (Pérez Luño, 1997, p. 225).

${ }^{8}$ Las mujeres en España no tuvieron acceso a la carrera judicial hasta 1966. En la actualidad ingresan más mujeres jueces que hombres en gran medida debido al Plan 14.02.2013 (Otero, 2013, p. 435).
} 
efectivamente quería ser esposa, madre de familia o ama de casa. Como decía Concepción Arenal, "la mujer sin instrucción científica, artística ni industrial, sin derechos, animal doméstico o ángel del hogar, vivía en él protegida de la sociedad” (1885, p. 251) ${ }^{9}$. El sexo femenino vivía aislado. Subsistía bajo una protección que alejaba a las mujeres de su propia realización personal impidiéndoles manifestarse como personas individuales e independientes.

Si analizamos las Constituciones Históricas de España observamos que ninguna de ellas permitía a la mujer desarrollarse. Tampoco lo hacían las normas de Derecho Canónico recogidas en el Corpus Iuris Canonici.

Voy a ofrecer algunos ejemplos extraídos de la normativa civil, mercantil, penal y canónica de lo que disponían las leyes históricas españolas sobre la mujer.

En el siglo XIX el Derecho Eclesiástico respondía a una visión del matrimonio, y por tanto de la mujer casada, que estaba más en función de la idea de que "se someterá la mujer a su marido y formarán una sola carne" (Efesios 5:22), que a otra que afirmaba: "mujer te doy y no esclava"10.

Para asentar mejor esta idea les ofrezco un extracto de un escrito fechado en 1840, muy ilustrativo de la situación de la mujer en el siglo XIX. Dice así:

Vos esposa, habéis de estar sujeta a vuestro marido en todo; despreciaréis el demasiado superfluo ornato del cuerpo, en comparación con la hermosura de la virtud; con gran diligencia habéis de guardar la hacienda; no saldréis de casa si la necesidad no os llevare, y esto con licencia de vuestro marido (Scanlon, 1976).

Este tipo de reflexiones, normales para la época, trasladaban un mensaje que la mayoría de las mujeres aceptaba como su destino, el mejor al que podían optar.

El Código Civil en vigor en España es de $1889^{11}$. Su contenido ha experimentado algunas modificaciones parciales, producto del cambio de circunstancias sociales, jurídicas y políticas experimentadas en España durante sus ciento treinta años de vigencia.

\footnotetext{
${ }^{9}$ La obra llena los tomos XV y XVI de las Obras Completas de Concepción Arenal, edición de Fernando García Arenal, publicadas en XXIII tomos entre 1894 y 1913.

${ }^{10}$, Este texto recuerda también al hombre la necesidad de amar a su mujer y formar una sola carne con ella. (Efesios 5:25 y 28)

${ }^{11}$ Fue dado en San Ildefonso el 24 de julio de 1889 por la reina María Cristina con el visto bueno, del ministro de Gracia y Justicia José Canalejas y Méndez.
} 
Entre ellas, figuran sin duda todas las referentes a la capacidad de la mujer y a la efectividad de sus derechos.

En la actualidad, todos los españoles somos iguales ante la ley sin que pueda prevalecer discriminación alguna por motivo de $\operatorname{sexo}^{12}$. Y, consecuentemente, todos debemos disfrutar de los mismos derechos. La mujer casada no está sometida al marido ${ }^{13}$; la mujer soltera no está sometida al padre ni al hermano; y las leyes no distinguen los derechos y deberes de los ciudadanos en función de la condición sexual que cada uno acredite $^{14}$.

Las leyes no discriminan, aunque siguen quedando vestigios de discriminación por sexo que sin duda deberán ser corregidos. Son vestigios de diferencia de salarios, de ocupaciones que parecen tener sexo preestablecido, de dificultad de acceso de la mujer a cargos directivos, etc. La realidad muestra que la mujer soltera está prácticamente equiparada al hombre. La mujer casada también, pero tiene que sortear muchas más dificultades. Para llegar a esta realidad ha habido que recorrer un camino largo de encuentros y desencuentros, el arduo camino del respeto por los derechos y por el reconocimiento de la dignidad del otro ${ }^{15}$.

Algunos ejemplos tomados de las leyes civiles ilustran el alcance de lo mencionado. La ley Civil vigente hasta la implantación del actual Código Civil español fueron las Partidas de Alfonso X el Sabio ${ }^{16}$. La Partida III, Título 4, Ley 4 negaba a las mujeres la posibilidad de ser jueces, negativa que se mantuvo en vigor hasta mediados del siglo $\mathrm{XX}^{17}$. De esta ley no me interesa tanto la prohibición que recogía, y que se mantuvo durante mucho tiempo, casi hasta la actualidad. Lo que realmente me interesa,

\footnotetext{
${ }^{12}$ El artículo 14 de la Constitución Española de 1978 dice: "Los españoles son iguales ante la ley, sin que pueda prevalecer discriminación alguna por motivo de nacimiento, raza, sexo, religión, opinión o cualquier otra condición o circunstancia personal o social".

${ }^{13}$ El Art. 32 de la Constitución Española de 1978 dice: "El hombre y la mujer tienen derecho a contraer matrimonio con plena igualdad jurídica".

${ }^{14}$ El artículo 12 de la Constitución Española de 1978 dice: "Los españoles son mayores de edad a los dieciocho años".

${ }^{15}$ Camino insoslayable, ya que "el Derecho se ha fundado por causa del ser humano y para beneficiarlo, o sea, para mantener y defender su dignidad espiritual y material, individual y social" (Otero Parga y Puy Muñoz, 2012, p. 266).

${ }^{16}$ Cito por la Edición de Las VII Partidas del muy noble rey D. Alfonso El Sabio glosadas por el Licenciado Gregorio López, del Consejo Real de Indias de S. M., Madrid, Compañía General de Impresores y Libreros del Reino, 1844.

${ }^{17}$ Partida III, Título 4, Ley 4: "No pueden ser jueces... Nin mugeres non lo pueden ser, porque non sería cosa guisada que estouiesse entre la muchedumbre de los omes, librando los pleytos". La prohibición no se extendía a la reina, o condesas, o dueñas, pero sólo en virtud de su señorío jurisdiccional. Tampoco podían ser jueces los locos, menores, ciegos o sordomudos.
} 
es mostrar la razón de la prohibición. La mujer no debía actuar como juez porque "no convendría al natural recato que debe observar la mujer, reunirse con hombres".

Una idea similar es la que se regula en la Partida V, Título 12, Ley 2, que niega a la mujer la posibilidad de ser fiadora ${ }^{18}$. De nuevo la razón que se esgrimía para esta prohibición era que resultar fiadora podría llevar a la mujer a tener que reunirse en lugares públicos con grupos de hombres, situación que iría en "contra de la castidad y buenas costumbres que debe respetar toda mujer".

En el mismo cuerpo legal aparecían otras disposiciones claramente discriminatorias, que ya no se referían a la reunión pública sino a un trato diferenciado basado en la capacidad. Así la Partida VII otorgaba siempre la primogenitura al varón sobre la hembra, aunque ambos hubieran nacido en un parto gemelar ${ }^{19}$. De modo que los derechos correspondientes al primer hijo nacido eran siempre para el hombre.

En sentido similar, la Partida VI, Título 16, Ley 4, determinaba que la mujer no podía ser tutora de huérfanos ${ }^{20}$; ni mantener la guarda de sus hijos una vez viuda si se volvía a casar ${ }^{21}$; ni actuar como testigo en un testamento ${ }^{22}$.

La mujer casada debía obedecer al marido ${ }^{23}$; debía seguirlo donde quiera que éste desease fijar su residencia ${ }^{24}$; debía consentir que su marido administrase todos sus bienes $^{25}$; no tenía capacidad para representarse a sí misma ${ }^{26}$; no podía adquirir nada sin

\footnotetext{
${ }^{18}$ Partida V, Título 12, Ley 2: "Otrosí dezimos que muger ninguna non puede entrar fiador por otro ca no sería cosa guisada, que las mugeres andouiessen en pleyto, por fiaduras que fiziesen auiendo a llegar a logares do que se ayuntan muchos omes, a usar cosas que fuessen contra castidad, o contra buenas costumbres, que las mugeres deuen guardar". A esta normativa general puede aplicársele alguna excepción recogida en la misma ley. Por ejemplo, sí podrían salir fiadoras las mujeres por razón de libertad, pero esa excepción cayó pronto en desuso, ya que se aplicaba únicamente a la manumisión de siervas.

${ }^{19}$ Partida VII, Título 33, Ley 12: "Nacen a las vegadas dos criaturas de una vez del vientre de alguna muger, e acontece que es dubda, qual dellas nasce primero, e dezimos que, si el uno es varón, e el otro fembra, que deuemos entender que el varón salió primero pues que non se puede anegar lo contrario".

${ }^{20}$ Partida VI, Título 16, Ley 4: "El que fuere dado por guardador de huérfanos non deue ser mudo, nin sordo, nin desmemoriado, nin desgastador, de lo que ouiere, nin de malas maneras. E deue ser mayor de veynte e cinco años, e varón, e non muger".

${ }^{21}$ Partida VI, Título 16, Ley 5: "Como la madre non puede auer sus fijos en guarda si se casare después de la muerte del padre dellos".

${ }^{22}$ Partida VI, Título 1, Ley 9: "Testiguar non pueden en los testamentos... nin moros... nin sordos... nin locos... nin las mugeres, nin los que fuesen menores de 14 años... nin siervos... nin mudos...".

${ }^{23}$ Artículo 57 del Código Civil Español de 1889: "El marido debe proteger a la mujer y ésta obedecer al marido".

${ }^{24}$ Artículo 58 del Código Civil Español de 1889: "La mujer está obligada a seguir a su marido donde quiera que éste fije su residencia".

${ }^{25}$ Artículo 59 del Código Civil Español de 1889: "El marido es el administrador de los bienes de la sociedad conyugal, salvo estipulación en contrario".

${ }^{26}$ Artículo 60 del Código Civil Español de 1889: "El marido es el representante de su mujer. Ésta no puede sin su licencia comparecer en juicio por sí o por medio de procurador".
} 
licencia del marido ${ }^{27}$; etc. El marido, por el contrario, no solo controlaba el patrimonio de la mujer, sino que también regía su consentimiento, pudiendo llegar a enajenar los bienes de la sociedad ganancial, a la que la mujer estaba obligada ${ }^{28}$, sin el consentimiento de esta $^{29}$.

La mujer soltera en este momento estaba sometida a limitaciones como la imposibilidad de abandonar la casa paterna sin licencia del padre o de la madre, aunque fuese mayor de edad, y siempre que no fuese mayor de 25 años $^{30}$.

Con estas leyes, hasta los mejor intencionados consideraban que la mujer debía ser protegida incluso de sí misma. Los hombres desconocían que el mayor síntoma de respeto por la dignidad de la mujer es considerarla capaz de asumir sus derechos, deberes y obligaciones.

Otro ejemplo aparece en el Código de Comercio de $1829^{31}$, que permitía contratar al varón menor, pero no a la mujer, con independencia de que esta fuese mayor de edad. La mujer casada solo podía ejercer comercio con consentimiento expreso del marido, dado en escritura pública. Y, aunque la mujer casada hubiera sido autorizada a comerciar por el marido, no podía hipotecar los bienes de ambos cónyuges en común, si la escritura de autorización no le había dado esa facultad expresamente ${ }^{32}$.

El panorama era bastante desolador y difícil de revertir.

En la actualidad afortunadamente las cosas son distintas tanto en Galicia como en España y aun en el mundo. Todavía no se ha alcanzado la plena equiparación de igual trabajo, igual capacidad, igual salario, pero sí se ha conseguido una concienciación de la sociedad. Pese a ello debemos seguir trabajando. Debemos reivindicar la igualdad dentro

\footnotetext{
${ }^{27}$ Artículo 61 del Código Civil Español de 1889: “Tampoco puede la mujer sin licencia o poder de su marido adquirir por título oneroso ni lucrativo, enajenar sus bienes, ni obligarse sino en los casos y con las limitaciones establecidas por la ley".

${ }^{28}$ Artículo 1393 del Código Civil Español de 1889: "La sociedad de gananciales empezará precisamente en el día de la celebración del matrimonio. Cualquier estipulación en sentido contrario se tendrá por nula". ${ }^{29}$ Artículo 1413 del Código Civil Español de 1889: "Además de las facultades que tiene el marido como administrador, podrá enajenar y obligar a título oneroso los bienes de la sociedad de gananciales sin el consentimiento de la mujer". Mientras que según el artículo 1416 del mismo cuerpo legal: "La mujer no podrá obligar los bienes de la sociedad de gananciales sin consentimiento del marido".

${ }^{30}$ Artículo 321 del Código Civil Español de 1889: "A pesar de lo dispuesto en el artículo anterior (que regula la mayoría de edad a los 23 años), las hijas de familia mayores de edad, pero menores de 25 años no podrán dejar la casa paterna sin licencia del padre o de la madre en cuya compañía vivan, como no sea para tomar estado, o cuando el padre o la madre hayan contraído ulteriores nupcias".

${ }^{31}$ Código de Comercio decretado, sancionado y promulgado en 30 de mayo de 1829. (1829).

${ }^{32} \mathrm{El}$ artículo 7 del Código de Comercio de 1829 dice: "La mujer casada que haya sido autorizada por su marido para comerciar no podrá gravar ni hipotecar los bienes inmuebles propios del marido, ni los que pertenezcan en común a ambos cónyuges, si en la escritura de autorización no se le dio expresamente esta facultad".
} 
de la diferencia. Debemos en suma reclamar para la mujer la equiparación que le permita disfrutar de idénticos derechos y deberes que el varón.

\section{Las mujeres viudas}

En el caso de las viudas el problema es aún mayor. Al hecho de ser mujeres se les suma la tristeza de perder a su marido, al compañero de vida. En esa situación han tenido que hacerse cargo de una vida que habían pensado de forma diferente. Sin embargo, han resistido. Han entendido que su vida no ha terminado, que son capaces de encargarse de sí mismas y de los demás, y que tienen un lugar en el mundo.

La sociedad les debe mucho y debería pagárselo al menos en la moneda del reconocimiento. Un reconocimiento que empieza a vislumbrarse por ejemplo con la declaración por la ONU del día 23 de junio como Día Internacional de las Viudas ${ }^{33}$. Esta celebración es particularmente importante y necesaria en países en los que los índices de discriminación son abrumadores.

Pensemos que todavía hoy en día, en algunos lugares del mundo, la viuda queda absolutamente desprotegida. Afortunadamente no están condenadas a morir y a ser sepultadas con el marido, como sucedía en algunas culturas hace un tiempo, pero sí tienen limitados sus derechos hereditarios. Su vida acaba dependiendo de la caridad de la familia del esposo. Además, y con mucha frecuencia, sufren violencia física. Su salud en ocasiones se ve quebrantada, debido a prácticas que dependen directamente de su condición de viudas. Por ejemplo, en algunos lugares de la India era costumbre obligar a la viuda a que bebiesen el agua con la que se había lavado el cadáver de su marido muerto. Y si el varón había fallecido de una enfermedad contagiosa, su viuda quedaba muy expuesta al contagio.

En nuestro entorno no es igual, pero permanecen muchas limitaciones como la dificultad de acceso a seguros o a préstamos, pues al ser solo un miembro de la familia el que puede hacerse cargo de la situación económica del colectivo, el prestador entiende que la fortaleza de la devolución del crédito se ve comprometida. De modo que en la práctica se castiga a la mujer y se menguan sus posibilidades de sacar adelante a su familia basándose precisamente en la circunstancia de la viudedad.

\footnotetext{
${ }^{33}$ Resolución de la Asamblea General de Naciones Unidas de 21 de diciembre de 2010, número 65/189.
} 
El problema se agrava pues se está produciendo un aumento progresivo de la población mayor que suele ser de mujeres, ya que en la actualidad acreditan una esperanza de vida superior al varón (casi el 90\% de viudas, frente al 10\% de viudos). Estas personas plantean problemas económicos y sociales como las pensiones de viudedad y orfandad, necesidades de colaboración económica en el sostenimiento de la familia, problemas de envejecimiento activo, atención a la dependencia, soledad, etc.

Las viudas necesitan dinero, por supuesto, pero precisan otras muchas cosas como atención especializada, compañía y sobre todo cariño.

Por educación, cultura y posiblemente vocación, las mujeres se han ocupado del cuidado de los otros. De los padres, de los hermanos, de los hijos, del marido. Y nunca se han mostrado débiles o necesitadas de cuidado propio, de tal manera que, para el resto, son personas que no necesitan nada, porque nada piden. Esta situación debe ser revertida, todas las mujeres, pero especialmente las viudas, tienen necesidad de ser ayudadas y atendidas en función de sus necesidades reales, y no únicamente por las quejas que manifiesten.

Esa atención debe proporcionárseles de la manera más completa posible. La familia no debería olvidar todo lo que debe a sus mayores. No debería hacerlo por simple instinto de conservación y de reciprocidad, pero sobre todo por amor.

Sin embargo, esto no es así. Los valores personales y familiares han cambiado y poco a poco muchas personas se sienten extrañas en sus propias casas. Los mayores se sienten cada vez más desconectados del mundo. Tampoco ayudan mucho los problemas auditivos que suelen padecer. Poco a poco se produce el aislamiento. De repente, hasta pedir una cita telefónica en el médico se convierte en todo un reto difícil de afrontar.

La consecuencia es la soledad que se ha convertido en una de las lacras de nuestra sociedad. Es necesario combatirla. La familia es el factor principal de ayuda, pero resulta muchas veces inoperante.

Sin embargo, la soledad bien administrada no debería ser un problema. De hecho, la soledad no debe interpretarse como un castigo, sino como una forma de relacionarse con uno mismo, que tiene que ser asumida y sobre todo dosificada.

Un rato de soledad hace mucho bien para conocerse a uno mismo. La soledad es buena, es interesante, te acerca a ti mismo y te ayuda a escuchar el silencio y así poder pensar. Pero debe ser una soledad momentánea y no permanente, buscada y no impuesta, 
deseada y no obligada. Debe ser una soledad equilibrada que al mismo tiempo te haga libre e independiente, sintiéndote querido y amparado.

Los límites a la libertad de antaño eran malos para el desarrollo de la personalidad, pero al menos, aseguraban al ser humano la permanencia en una familia hasta la muerte. Una familia que iba creciendo y que se nutría de futuras generaciones. Hoy no es así. La libertad y el ejercicio de la responsabilidad de los seres humanos, ha dado lugar a una vida más individualizada pero más solitaria. En la actualidad, se mueren algunas personas en sus casas y sus cadáveres se encuentran días e incluso meses o años más tarde porque

nadie las ha echado de menos. Ésa es una soledad que no debe consentir la familia, ni la sociedad.

No podemos convertirnos en una sociedad deshumanizada. No podemos entregarnos, ni permitir que otros se entreguen, sin buscar la mejor vida que puedan desarrollar en las distintas facetas de su vida. La vida nunca puede ser indigna.

Y para ello es primordial que la sociedad valore a la gente.

Pero antes de eso incluso, es fundamental que cada una de nosotras nos valoremos a nosotras mismas. Las viudas no eran personas más valiosas cuando tenían maridos. Ellas, como el resto de las personas, siempre fueron importantes por sí mismas. Así deben sentirse y así debe percibirlas la sociedad.

\section{Algunas medidas de protección para las viudas}

Sin embargo, no es así, y tanto las familias como la sociedad olvidan a sus mayores. Urge tomar medidas que dulcifiquen esta situación. A continuación, ofrezco algunas de ellas en las que está trabajando el gobierno gallego en la actualidad y que pueden servir como punto de partida para mejorar la situación de las personas viudas.

1. Es fundamental potenciar la obligación de los poderes públicos de proporcionar una atención de calidad a las personas mayores sin limitarse exclusivamente a los dependientes. Las personas mayores no dependientes también necesitan ayuda, aunque esta sea de otro tipo. Es necesario potenciar centros de reunión, actividades académicas y de distintos tipos de formación, y una variada oferta cultural que les permita tejer un círculo de amistades que alejen el fantasma de la soledad.

2. También conviene ofrecer a las personas maduras, la posibilidad de ser útiles a los demás a través de programas de voluntariado o similares, que les hagan sentirse 
partícipes activos de la sociedad, y que al mismo tiempo les permitan ayudar en muy diversos campos. Esta ayuda debe proporcionarse respetando su ámbito de vida, pues alejar a las personas de su entorno conocido suele producir una sensación de desarraigo incompatible con el deseo de paliar la soledad.

3. Este problema se hace especialmente importante si nos referimos a las personas que deciden o necesitan vivir en residencias. Hoy en día las residencias privadas son muy caras y las públicas no consiguen ofrecer el número de plazas necesarias para nuestra gente.

4. Es habitual que las personas mayores presenten además problemas de salud. Para ayudarlas se deben incentivar los programas de teleasistencia, servicios de atención en el hogar, prestaciones por cuidados en el entorno familiar y programas de envejecimiento activo. Estos servicios claro está, no son exclusivos de mujeres viudas, pero lo cierto es que, en la práctica, se dan mucho más en esa situación porque hay muchas más mujeres mayores viudas que hombres mayores viudos.

Es preciso considerar que todos estos programas necesitan de un importante desembolso económico, pero lo cierto es que lo valen. Mi experiencia me permite afirmar la existencia de algunas mejoras a implementar para tratar de solucionar todos estos graves problemas de falta de recursos para la dependencia, ayuda a los mayores, centros de día, etc.

5. También se detectan dificultades por la falta de medios de transporte con la frecuencia y número de paradas que gustarían a los mayores, especialmente en hospitales. Este problema es especialmente acuciante en los lugares con una gran dispersión de población y con un índice cada vez más elevado de personas mayores.

Así las cosas, algunos gobiernos están potenciando los programas de voluntariado y de acompañamiento de determinadas ONG. Estos programas promovidos por la ley están dando buen resultado pues involucran a muchas personas probando que, a pesar de todo, aún existe una conciencia social grande y un espíritu de solidaridad prometedor, que ejercitan muchas personas jóvenes y no tan jóvenes, que sienten que tienen algo que ofrecer a las personas que más los necesitan. Iniciativas como estas deberían ser promovidas, alentadas y protegidas.

Por último, debo referirme a los problemas económicos que arrastran muchas personas viudas por falta o insuficiencia de recursos económicos. Con independencia del 
hecho de que esa persona hubiera trabajado y de que por tanto tuviera el derecho a una pensión, lo cierto es que mientras vivía con el otro cónyuge se sumaban las dos pensiones, pero al quedarse sola, a todos los problemas de soledad ya comentados, se une muchas veces la rebaja económica importante, que suma un elemento más de preocupación en el momento de la muerte del compañero. Muchas veces las pensiones de viudedad son insuficientes. Es necesario que los poderes públicos revisen sus prioridades y aún en escenarios económicos poco o nada favorables, sean capaces de priorizar estas necesidades para obrar con justicia.

\section{Conclusión}

En fin, la viudedad supone problemas, tristezas y soledades. El fundamental es sin duda la muerte del compañero, del ser amado, de la persona con la que se había decidido compartir la vida. Pero este problema, con ser tan penoso, no es el único. Después surgen otros de carácter económico en muchos casos, y de toma de decisiones y gestiones en otros. En las parejas, cada uno de los miembros suele ocuparse de hacer unas cosas concretas. Las tareas no siempre están bien divididas, pero desde luego existen. En el momento en que falta una de las partes, la otra se da cuenta de que hay muchas cosas que no sabe hacer, que le cuesta decidir, que no conoce, o que no entiende. Hay decisiones que tomar sin conocer los antecedentes, hay inversiones que hacer o que rescatar... en fin, un conjunto de situaciones que muchas veces hace insufrible una vida ya de por si triste y dolorosa.

En ese momento se acude a la familia y a los amigos, pero en muchos casos no es suficiente. La testamentaria, las particiones hereditarias de los hijos en su caso, el pago de los impuestos... Es difícil de hacer y de entender, lento, doloroso, farragoso, desesperante. Y además llega en los peores momentos, pues se tiene que hacer los seis primeros meses desde el fallecimiento del compañero. Ahí sucumben muchas personas...

Es verdad que poco a poco la vida va dando otras opciones. No se trata de olvidar, sino de aprender a vivir con los recuerdos. Pero es muy difícil hacerlo, y hay que tener mucha valentía para lograrlo con éxito.

Pese a ello muchas viudas y muchas personas mayores lo consiguen. Lo hacen con presencia de ánimo y con esfuerzo personal. Encarando su vida con coraje. Ellos son el principal valor sin duda, pero necesitan la ayuda de la sociedad, de los gobiernos y de 
las leyes. Necesitan retomar el puesto en la sociedad que nunca se les debió negar, porque lo antiguo, o con años, no es peor por tenerlos, de la misma manera que no es mejor lo nuevo simplemente por carecer de ellos. Cada persona será merecedora de aquello por lo que esté dispuesta a luchar de la misma manera que cada sociedad en su conjunto será responsable de los medios que ponga a su servicio para conseguirlo.

\section{Referencias}

Arenal, C. (1885). El Pauperismo. Tomo I. Madrid, España: Librería de Victoriano Suárez Rivadeneyra.

Burgoa, I. (2002). Las garantías individuales. México D. F., México: Porrúa.

Dworkin, R. (1984). Los derechos en serio. Barcelona, España: Ariel-Derecho.

Imbert. P. H. (1996). Los derechos humanos en la actualidad. En A. E. Pérez Luño, Derechos Humanos y Constitucionalismo ante el tercer milenio (pp. 11-52), Madrid, España: Pons.

Nino, C. S. (1991). Introducción al análisis del Derecho. Barcelona, España: ArielDerecho.

Otero Parga, M., y Puy Muñoz F. (2012). Jurisprudencia Dialéctica. Madrid, España: Tecnos.

Otero Parga, M. (2013). Una mujer juez. A propósito del Plan 14.02.2013 de igualdad de la carrera judicial. Dereito. Revista Xurídica da Universidade de Santiago de Compostela, 22, 435-467.

Pérez Luño, A. E. (1997). Teoría de los Derechos Humanos. Madrid, España: Tecnos.

Puy Muñoz, F. (1978). El derecho a la dignidad. En F. Rodríguez y J. Iturriaga (Eds.), Homenaje a Eleuterio Elorduy S. J (pp. 263-274). Bilbao, España: Universidad de Deusto.

Puy Muñoz, F. (1983). Derechos Humanos. Santiago de Compostela, España: Imprenta Paredes.

Scanlon, G. M. (1976). La polémica feminista en la España contemporánea (1868-1974). Madrid: Akal.

Truyol Serra, A. (1984). Los Derechos Humanos. Madrid, España: Tecnos. 


\section{Textos legales}

Real Decreto de 24 de julio de 1889, de Código Civil Español, (Gaceta de Madrid nº 206 de 25/07/1889).

Real Decreto de 22 de agosto de 1885 de Código de Comercio Español (B.O.E. n ${ }^{\circ} 289$ de 16/10/1885).

Constitución Española de 1978, (B.O.E. no 311 de 29/12/1978).

Las VII Partidas del muy noble rey D. Alfonso El Sabio glosadas por el Licenciado Gregorio López, del Consejo Real de Indias de S. M., (Madrid: Compañía General de Impresores y Libreros del Reino, 1844).

Resolución de la Asamblea General de Naciones Unidas número 65/189, de 21 de diciembre de 2010.

\section{Contribución autoral}

a) Concepción y diseño del trabajo; b) Adquisición de datos; c) Análisis e interpretación de datos;

d) Redacción del manuscrito; e) revisión crítica del manuscrito.

M. M. O. P. ha contribuido en a, d, e.

\section{Editor responsable}

Dr. Pablo Rodríguez Almada 